\title{
Avrupa Birliği'nde Kamu Borç Stokunun Ekonomik Büyümeye Etkisi: Panel Veri Analizi ${ }^{1}$
}

Burcu BERKE, Department of Economics, Faculty of Economics and Administrative Sciences, Nigde University, Turkey; e-mail: burcuberke@nigde.edu.tr

\section{The Impact of Public Debt Stock on Economic Growth in European Union: Panel Data Analysis ${ }^{2}$}

\begin{abstract}
In this study, what effects on the growth rate of the increase in public debt are analyzed with panel data model during the period 1970 to 2011 in EU-13. In the literature, it is pointed out that reducing of the rate of growth while the public debt to GDP ratio is over $90 \%$ of the threshold value. These findings have led to draw attention to the issue of financial instability in developed and developing countries. In this study, after controlling the effects of other control variables other than public debt, it has been identified that the effects on the growth of the public debt are negative if the threshold value exceeds $90 \%$ in the EU-13.
\end{abstract}

Keywords : : Public Debt Stock, Growth, Panel Data Analysis.

JEL Classification Codes : $\quad$ E6, E3, C33.

\section{$\ddot{\mathbf{O} z}$}

Bu çalışmada, AB-13'de 1970-2011 döneminde kamu borç stokunun artmasının büyüme oranını ne yönde etkilediği panel veri yöntemiyle incelenmektedir. Literatürde "kamu borç stokunun GSYİH'ye oranının \%90 eşik değerinin üzerinde iken büyüme oranının düştüğüne" işaret edilmektedir. $\mathrm{Bu}$ bulgu, gelişmiş ve gelişmekte olan ülkelerde mali istikrarsızlık konusuna dikkat çekilmesine yol açmıştır. Çalışmada, büyümeyi etkileyen kamu borç stoku değişkeni dışında diğer kontrol değişkenlerinin etkileri kontrol edildikten sonra AB-13'de kamu borcunun büyümeye etkisinin $\% 90$ eşik değerinin üzerinde negatif olduğu tespit edilmiştir.

Anahtar Sözcükler $\quad$ : Kamu Borç Stoku, Büyüme, Panel Veri Analizi.

I Bu çalışma, İspanya'da bulunan Castilla La Mancha Üniversitesi, Ekonomi bölümünde ziyaretçi araştırmacı olarak bulunduğum sırada yapılmıştır. Değerli yorumları ve katkıları için Prof. Dr. Oscar Bajo-Rubio ve hakemlere teşekkür ederim.

2 This study was done when I was in Spain as a visiting scholar at the department of Economics at the University of Castilla La Mancha. For their valuable comments and contributions, I am very thankful to Prof. Dr. Oscar Bajo-Rubio and two anonymous referees. 


\section{Giriş}

1980'li yıllardan itibaren birçok çalışmada "borç krizi" veya gelişmekte olan ülkelerin borç problemine dikkat çekilmiş (Krueger, 1987) ve bu yılların ardından bu ülkelerin çoğunda, borç stokunun artmasının büyüme oranını düşürdüğü ileri sürülmüştür. Bunun yanı sıra, etkinsiz döviz kuru ayarlamalarının bir sonucu olarak dış piyasalarda rekabetçi yapı kaybı (dış ticaret hadlerinin ülkelerin aleyhine dönmesi), yanlış iktisat politikaları ve yaşanan krizler, bu ülkelerde büyüme oranlarının düşmesine katkı sağlamıştır (Siddıqui \& Malik, 2001: 677).

Küresel krizin sonrasında gelişmiş ülkelerde (ve özellikle avro bölgesinde) borçların artmasının mali sürdürülebilirlik yönünden olumsuzluk yarattığı görülmektedir (Greenidge vd., 2012: 3). Temel konu, gelişmiş ve gelişmekte olan ülkelerde borçların artmasının verimlilik ve sermaye birikimini azaltarak ekonomik büyümeyi düşürüp düşürmediğidir. Buna neden olabilecek faktörler ise şöyledir: yüksek enflasyon ve faiz oranları, saptırıcı vergiler ile belirsizlik. Bu koşullarda, belki de borç sürdürülebilirliği ile büyümedeki düşüş belli ölçüde engellenebilir (Kumar \& Woo, 2010: 4).

Literatürde, teorik olarak kamu borcunun belli bir eşik değerinin üzerinde büyümeyi olumsuz etkileyebileceği tartışılırken, konuya ilişkin uygulamalı çalışmalar ise kıttır (Reinhart \& Rogoff, 2010; Greenidge vd., 2012). Mevcut çalışmalarda, gelişmekte olan ülkelerde $d \iota s ̧$ borcun büyümeye etkisine odaklanılmış ve kamu borcunun büyümeye etkisi ise uzun vadeli faiz oranları üzerinden dolaylı olarak ifade edilmiştir. Küresel kriz avro bölgesinde (euro area) borç stokunu arttırıp kamu finansmanı yönünden güçlükler yarattığından, bu bölgede bütçe açığının GSYİH'ye oranının hızla artacağı ve dolayısıyla, brüt kamu borç stokunun GSYİH'ye oranının (borç yükü) da yükseleceği beklenmiştir (Checherita \& Rother, 2010: 6, 8). Bu koşulların avro bölgesinde uzun vadeli mali sürdürülebilirliği kötüleştirirken, yüksek ve kalıcı kamu borçlarının bir yandan büyüme oranını düşürüp düşürmeyeceği, diğer yandan ise borç yükünün artışına katk1 sağlayabileceği merak konusudur. Tüm bunlar, borç ve büyüme ilişkisinin avro bölgesi için ele alınmasını ilgi çekici hale getirmektedir.

Yukarıdaki ifadelerden anlaşıldığı üzere, gelişmiş ülkelerde küresel krizlerin sonucunda kamu borcunun canlanmasılyla kamu borcu ve büyüme ilişkisine yönelik tartışmalar oluşmuştur. Ayrıca, küresel krizle birlikte, tüm gelir düzeylerindeki ülkelerde kamu borç stokunun artarak kalıcı olabilme riski taşıması ve artan bu borcun, büyümeyi yavaşlatıp yavaşlatmadığı veya borcun, veri bir eşik değerinin üzerinde iken büyümeyi ne yönde etkileyebileceği sorgulanmaya başlanmıştır (Cecchetti \& Mahonty \& Zampoli, 2010; Balassone \& Francese \& Pace, 2011). Bu noktada, Reinhart ve Rogoff (2010)'un kamu borcunun GSYİH'ye oranının \%90 eşik değerinde iken büyüme oranını düşürdüğünü dile getirmeleri ve daha son olarak ise Greenidge vd. (2012)'nin bu eşik değerin \%56 düzeyine gerilediğini ifade etmeleri, borç ve büyüme ilişkisinin çalışılmasını cazip hale getirmiştir. 
Berke, B. (2016), “Avrupa Birliği'’nde Kamu Borç Stokunun Ekonomik

Büyümeye Etkisi: Panel Veri Analizi”, Sosyoekonomi, Vol. 24(27), 121-137.

Bu çalışmada, Avrupa Birliği'ne seçilmiş üye ülkelerde (AB-13) "kamu borç stokundaki değişmelerin büyümeyi ne yönde etkilediği" hipotezi panel veri yöntemi ile analiz edilmektedir. Çalışmanın takip eden kısmında, konu ile ilgili teorik ve ampirik çalışmalara yönelik bir yazın incelemesi sunulmaktadır. Üçüncü kısımda, model, veri seti ve yöntem tanıtılırken, dördüncü kısımda analiz sonuçlarına ve son olarak ise çalışmanın sonucuna yer verilmektedir.

\section{Yazın İncelemesi}

Küresel kriz, özellikle gelişmekte olan ülkelerde "kamu borç stokunun artmasının büyümeyi ne yönde (olumsuz mu?) etkilediğinin” sorgulanmasına yol açmıştır (Balassone, Francese \& Pace, 2011). Bu kapsamda kamu harcamasının verimli mi yoksa verimsiz mi olduğu büyümeyi farklı etkileyebilmektedir. Örneğin, verimsiz bir kamu harcamasının vergilerle finanse edilmesi büyümeyi azaltırken, verimli bir kamu harcamasının aynı şekilde karşılanması ise büyümeyi arttırabilmektedir. Ancak, yüksek borç oranı, bu verimli harcamanın büyüme arttırıcı etkilerini azaltabilmekle birlikte bütçe açıklarının vergilerin yanı sıra para basılarak finansmanı büyümeyi arttırırken borç ile finansmanı ise büyümeyi azaltabilmektedir (Adam \& Bevan, 2005: 577, 579).

Sermayenin hareketli veya hareketsiz olması da büyümeyi farklı şekillerde etkilemektedir. Örneğin, ülkelerin borç vermesine izin verildiği sermaye hareketliliğinde (geleneksel neoklasik modeller) büyüme oranı belli ölçüde artarken, sermaye hareketsiz iken ise ülkenin borçlanarak yatırım yapması, sermayenin marjinal ürününün, dünya faiz oranını aşmasına bağlıdır (Chowdhury, 2001: 4).

Ülkeler kalkınmalarının başlangıcında düşük sermaye stokları ve dolayısıyla, sınırlı yatırım fırsatlarına sahip olup hem yüksek getiri sözü verirler hem de bunların makul miktarda borçlanmaları, verimlilik artışı üzerinden büyümeyi canlandırabilir. Ancak, bu ülkeler borçlarını verimli yatırımlarda kullanmadıkları sürece, yatırım ve verimlilik artışları engelleneceğinden büyümeleri de zarar görebilmektedir (Hameed \& Ashraf \& Chaudhory, 2008: 132). Yüksek borç, orta ve uzun vadeli büyümeyi birkaç kanal ile olumsuz etkileyebilir: (i) İlki, yüksek kamu borcunun, yüksek uzun vadeli faiz oranlarıyla sermaye birikimi ve büyümeyi olumsuz biçimde etkileyebilmesidir. (ii) İkincisi ise bu borç krizinin yüksek saptırıcı vergileme, enflasyon ve politikalardaki belirsizlik ile birleşerek diğer kriz türleriyle (bankacılık veya para krizi) tetiklenmesi ve dolayısıyla, borcun büyümede yaratabileceği olumsuz etkileri büyütmesidir. Bu noktada "kamu borcu büyümeyi etkiler mi? etkilerse ne yönde etkiler?" sorularına yanıt aranmalıdır. Geleneksel görüş, kamu borcunun kısa dönemde toplam talep ve çıktıyı teşvik edebileceğini (Keynesyen olmayan etkilerin yokluğu), ancak, uzun dönemde ise sermayeyi dışlayıp çıktıyı azaltacağını belirtir (Kumar \& Woo, 2010: 5).

Diamond (1965), vergilerin sermaye stokuna etkisini inceleyip kamusal iç ve diş borçları ayırarak bu borç türlerinin vergi ödeyicilerin tasarruflarının yanı sıra yaşam boyu tüketimlerini ve sermaye stoklarını azalttığını dile getirmiştir. Bu noktadan sonra literatürde 
özellikle gelişmekte olan ülkelerde borçlanmanın "makul” düzeylerinin sermaye birikimi ve verimlilik artışıyla büyümeyi arttırabileceği öngörülmüştür (Pattillo \& Poirson \& Ricci, 2004: 5; Checherita \& Rother, 2010: 10). Geleneksel neoklasik modellerde, tam sermaye hareketliliği borç ve büyüme ilişkisini pozitif kılarken, aslında borç yükü, büyümeyi ters yönde de etkileyebilir. Bu etki bir yandan, borç stoku ve faiz kanalları üzerinden işlerken, diğer yandan yüksek borç finansmanının kamu yatırımını caydırması anlamına gelen "dışlama" (crowding out) etkisiyle de olabilmektedir. Böyle bir ortam, kamu gelirlerini artırırken, mevcut paranın verimli yatırımlardaki payını azaltmaktadır (Presbitero, 2005: 3). Bunların dişında literatürde yüksek borcun büyümeyi olumsuz etkileyebildiği iki temel kanal vardır: Bunlardan ilki "borç uzantısı" (debt overhang) teorisi iken, diğeri ise "belirsizlik (uncertainty)"tir (Pattillo \& Poirson \& Ricci, 2004: 5).

(i) Borç uzantısı teorisi, borç ve büyüme ilişkisinin negatif olduğunu ortaya koymaktadır (Krugman (1988), Sachs (1989), Cohen (1993)). Bu teoride, temel fikir, yüksek bir borç yükünün gelecekteki vergiler ve/veya borç krizleri nedeniyle özel yatırıma yönelik bir isteksizlik yaratarak büyümenin itici bir gücü olan yatırımları daraltmasıdır (Chowdhury, 2001: 3; Presbitero, 2008: 2). Beklenen faiz ödemeleri, çıktı ile pozitif ilişkili iken, yüksek borç stoku yatırımları düşürerek büyümeyi yavaşlatmaktadır (Presbitero, 2005: 3). Bu teoriyi ilk olarak Krugman (1988: 254, 255) ortaya atmış olup çalışmasında borç uzantısını, "kreditörlerin borçların tamamen geri ödenmesini güvenle beklemedikleri miktarda miras kalan "yüksek borç” şeklinde tanımlamıştır. Dolayısıyla, bir ülkenin gelecek kaynaklarının beklenen bugünkü değeri, mevcut borcundan daha düşük iken, borç uzantısı problemi var demektir (Weng, vd., 2011: 14).

Bir ülke, borç uzantısı problemi ile karşı karşıya iken, ülkenin borcunu geri ödememe olasılığı yükselir (Daud \& Podivinsky, 2011). Cohen (1993) yüksek borcun her zaman yatırımları düşürmediğini, ancak, borcun geri ödenmeme oranının, yatırımı dışladığını dile getirmiştir. Bu bağlamda, borç ve yatırım ilişkisi büyümeye genişletilerek belli bir eşiğe kadar dış borç birikiminin, yatırım ve büyümeyi arttırabilirken, böyle bir noktanın ötesinde ise borç uzantısının, yatırım ve dolayısıyla büyümede negatif bir etki yarattığ1 ortaya konulmuştur (Clements \& Bhattacharya \& Nguyen, 2003: 4; Checherita \& Rother, 2010: 10). Gelecekteki borç, ülkenin borcunu geri ödeme gücünden yüksek iken, beklenen borç finansman maliyetleri, üretimle birlikte doğru orantılı değişmektedir. $\mathrm{Bu}$ koşullarda, ulusal ve yabancı yatırımlar vergilendirilerek caydırılırken, büyüme oranı da düşebilmektedir. Böyle bir durumda, yatırımcılar, üretimlerini arttırmaktan korkarlar, borçlarını karşılamak için kreditörlerce daha fazla vergilendirilirler, böylece, gelecekte üretimlerinin artması uğruna bugünden yatırım maliyetlerine katlanma istekleri azalır ve getiri beklentilerini düşük tutarlar (Sıddıqui \& Malik, 2001: 682; Pattillo \& Poirson \& Ricci, 2004: 5; Hameed \& Ashraf \& Chaudhory, 2008: 134; Weng, vd., 2011: 13). Dolayısıla, yüksek borçluluk, bir yandan, gelecek üretimde bir vergi işlevi görerek finansal anomaliler (teşviksizlik, nakit akımı ve ahlaki riziko etkileri) sonucu tasarruflar ile yatırımları düşürüp büyümeyi zedelerken, diğer yandan, yatırım ve politikalardaki ters etkileriyle büyüme oranını düşürmektedir (Fasu, 1996: 97; Sen \& Kasibhotlo \& Stewart, 2007: 3, 4; Daud \& 
Berke, B. (2016), “Avrupa Birliği’nde Kamu Borç Stokunun Ekonomik

Büyümeye Etkisi: Panel Veri Analizi”, Sosyoekonomi, Vol. 24(27), 121-137.

Podivinsky, 2011: 3). Borcun düşük düzeyleri zıt sonuçlara neden olurken, ara durumlarda ise borcun büyümeye etkisi belirsizdir (Sıddıqui \& Malik, 2001: 682).

Nominal borç stoku ve yatırım ilişkisi "borç-Laffer eğrisi” ile gösterilebilir. Bu eğride, yüksek borç stoku, düşük borç ödeme olasılığı demektir. Eğrinin yukarıya doğru eğimli tarafında nominal borç değerinin artması, beklenen borç ödemesini arttırırken, eğrinin aşağıya doğru eğimli tarafinda ise borcun artması beklenen borç ödemesini azaltır. Borcun belli bir kısmının affedileceği beklentisi, yatırımcıları yeni finansman sağlamaktan caydırarak sermaye birikimini düşürmektedir (Clements \& Bhattacharya \& Nguyen, 2003: 4; Pattillo \& Poirson \& Ricci, 2004: 5). Düşük borçlu ülkeler için borç birikimi yüksek büyüme oranları yaratmasına karşın, yüksek borçlu ülkeler için ise aynı şeyi söylemek mümkün değildir. Bu ülkelerde Laffer eğrisi, borç yükünün düşmesinin büyüme olasılığını arttırdığını ve böylece, borç yükü artışının ise olumsuz olabildiğini gösterir (Cunningham, 1993: 116; Bhattacharya \& Clements, 2004: 49). Dolayısıyla, borç stoku belli bir eşik değerinin üzerinde iken, borcun beklenen geri ödemesi, bu ters etkinin bir sonucu olarak düşmeye başlamaktadır. Yukarıya doğru eğimli eğrinin etkisi, nominal borç artışının eşik düzeyine kadar beklenen geri ödemeyi artırmasıdır. Laffer eğrisinin aşağıya doğru eğimli (yanlış) tarafında ise nominal borç artışı sonucu, borcun beklenen geri ödemesi azalmaktadır (Daud \& Podivinsky, 2011: 4).

Yüksek borç finansmanı, bir yandan, hükümetin faiz harcamasını ve bütçe açığını arttırırken, diğer yandan ise kamu tasarruflarını azaltır, bu durumda ya ulusal faiz oranları artabilir ya da özel yatırıma yönelik krediler dışlanabilir. Buradan, yüksek borç ödemelerinin büyümeyi olumsuz etkileyerek yatırımlar için mevcut kaynak miktarını azaltabildiği görülür (Clements \& Bhattacharya \& Nguyen, 2003: 5; Bhattacharya \& Clements, 2004: 49).

(ii) Belirsizlik: Yüksek borçlu ülkelerde, borcun ülkelerin kendi kaynakları ile ödenebileceğine ilişkin belirsizlikler olup (Weng, vd., 2011: 14) bu türden bir borcun makroekonomiyi belirsiz kıldığı ve bu etkinin sadece temel göstergelerin (faiz oranları, döviz kurları, enflasyon) değişkenliği ile ilgili değil, aynı zamanda politika ve kurumsal çerçeve ile de ilgili olduğu görülmektedir (Presbitero, 2005: 3). Yüksek borçlu ülkelerde borcun ne kadarının ülkelerin kendi kaynakları ile karşılanacağına ilişkin belirsizlikler veri iken hem yatırımcılar yeni yatırımlar konusunda çekingen davranabilmekte hem de kaynaklar sermayenin verimliliğini yavaşlatan daha yoksul yatırım projelerine ayrılarak yanlış dağılabilmektedir (Pattillo \& Poirson \& Ricci, 2004: 3-6).

Literatürde incelenen iki temel soru "yüksek borç daha düşük büyümeye mi neden olmaktadır? veya düşük büyüme borcu arttırmakta mıdır?” şeklindedir. Teorik literatür nedenselliğin her iki yönüne de dikkati çekmiştir (Pattillo \& Poirson \& Ricci, 2004). Ancak, nedensellik sadece yüksek borçtan düşük büyümeye doğru değil düşük büyümeden yüksek borca doğru da olabildiğinden (zit yönlü nedensellik) (Kumar \& Woo, 2010: 7; Balassone \& Francese \& Pace, 2011: 2) borcun büyümeye negatif etkisinin varlığg savunulurken dikkat edilmelidir. Çünkü daha düşük büyüme, vergi gelirleri ve birincil bütçe fazlalarını düşürmekte, bütçede bir ayarlama olmaksızın borç oranlarını ise giderek artırmaktadır 
(Pattillo \& Poirson \& Ricci, 2004: 8). Easterly (2001) bu ters nedensellik ilişkisini vurguladığı çalışmasında, 1970'li yıllarda görülen dünya çapındaki büyüme daralmasının negatif bir mali şok yaratarak daha düşük büyümenin vergi gelirleri ve birincil bütçe fazlalarının bugüne indirgenmiş değerini giderek düşürdüğünü ve böylece veri bir borç yükünü arttırdığını dile getirmiştir.

Borç uzantısı ve belirsizlik argümanları borç ve büyüme arasında doğrusal olmayan bir ilişkiyi ortaya koymaktadır. Borcun makul düzeyleri büyümede pozitif bir etkiye sahip iken yüksek borç stoku ise büyümeyi kısıtlayabildiği için borç, büyümede pozitif veya negatif bir etki yaratabilmektedir (Sıddıqui \& Malik, 2001: 682, 683; Ramakrishna, 2002: 29). Reinhart ve Rogoff $(2010$ : 575, 577) borç ve büyüme ilişkisini inceleyerek borç için bir eşik değer hesaplayan öncül bir çalışmadır. İlgili çalışmada borcun düşük veya 1lımlı düzeyinde borç ve büyüme arasında hiçbir ilişki olmadığına dikkat çekilmiştir. Diğer yandan, yazarlar, gelişmiş ülkelerde borcun GSYİH'ye oranı \%90'nın üzerinde iken ortalama büyüme oranı \%1'den daha düşük olup, gelişmekte olan ülkeler için ise bu oranın \%2.9'a düştüğünü tespit etmişlerdir. Bu çalışma, yüksek borç düzeylerinin, daha düşük büyümeyle sonuçlanabildiğini göstermiştir. Ancak, Reinhart ve Rogoff (2010) sadece kamu borç stokundan büyümeye doğru olan bir ilişkiyi vurgulamışlar ve ters nedensellik (düşük büyümenin yüksek kamu borcu yaratması) meselesini ve büyümenin diğer unsurlarını ihmal etmişlerdir (Irons \& Bivens, 2010: 1; Kumar \& Woo, 2010: 8).

Literatürde, yüksek borçlu gelişmekte olan ülkelerde görülebilen borç ve büyüme arasındaki negatif ilişsinin varlığı yaygın olmasına karşın, bu duruma yönelik ampirik çalışmalar sınırlıdır (Cunningham, 1993). Çalışmalar genellikle gelişmekte olan ülkelerde $d$ lş borcun büyümeye etkisine odaklanırken, gelişmiş ülkelere yönelik analizlerde ise avro bölgesi yoktur. Avro bölgesi hükümetleri, hem mali politika yönünden özgür oldukları hem de bu ülkelerde finansal krizlerin ardından borç yükleri giderek arttığından mali baskı ile karşı karşıyadırlar ve dolayısıyla, bu türden analizler avro bölgesi için daha uygundur (Checherita \& Rother, 2010: 9). Ayrıca, AB ülkeleri yüksek borç düzeyleri veya düşük büyüme riski ile yüzleştiklerinden mali konsolidasyonla refahları artabilmekle birlikte, bu bölge geçmiş finansal krizlere karşı bağışıklıklarına karşın, bu krizlerle birlikte kamu finansmanlarının kötüleştiği ve resesyon ile karşılaşarak sürpriz yaşadıkları görülmüştür. Bu ülkelerde belki de temel sorun, rekabetçi yapılarında zorluk çıkaracak olan "döviz kuru ayarlama” imkânlarının olmamasıdır (Barrios \& Langedijk \& Pench, 2010: 2).

Son olarak, yüksek borçlar, sadece makroekonomik performansla ilgili olmayıp politik ve kurumsal yönlerle de ilgilidir. Bu borçlar, büyümeyi arttırıp yoksulluğu azaltmayı amaçlayan yapısal reformların etkinliğini ve güçlü kurumların gelişimini zedeleyebilmektedir (Presbitero, 2005).

Konu ile ilgili ampirik çalışmaları üç yönden sınıflandırmak mümkündür. Bunlardan ilki, borç uzantısı hipotezi bazında ilerleyip borçların büyümeyle ilişkisini analiz eden çalışmalardır [(Cohen (1993), Cunningham (1993), Fasu (1996), Mbire \& Atingi (1997), Chowdhury (2001), Siddiqui \& Malik (2001), Ramakrishna (2002), Schalarek 
Berke, B. (2016), “Avrupa Birliği’nde Kamu Borç Stokunun Ekonomik

Büyümeye Etkisi: Panel Veri Analizi”, Sosyoekonomi, Vol. 24(27), 121-137.

(2004), Presbitero (2005), Sen, Kasibhotlo \& Stewart (2007), Hameed, Ashraf ve Chaudhory (2008), Daud \& Podivinsky (2011)]. İkincisi, borç stoku için bir eşik değer hesaplayarak borçların büyümeye doğrusal olmayan etkisini analiz eden çalışmalardır [Clements \& Bhattacharya \& Nguyen (2003), Bhattacharya \& Clements (2004), Pattillo \& Poirson \& Ricci (2004), Adam \& Bevan (2005), Cecchetti \& Mahonty \& Zampoli (2010), Checherita \& Rother (2010), Balassone \& Francese \& Pace (2011), Greenidge vd., (2012)]. Üçüncüsü ise politika ve kurumlara göre borçların büyümeye etkilerini değerlendiren çalışmalardır [Cordella \& Ricci \& Ruiz-Arranz (2005) ve Presbitero (2008)].

İlk çalışmalar, az gelişmiş ülkelerde borcun büyümeye etkisini incelerken "dış borcun tasarruf ve yatırım düzeylerine etkilerine" bakmışlardır (Fasu, 1996). Sachs (1989) ve Cohen (1993) dış borç ve yatırım arasında anlamlı bir negatif ilişkiye dikkati çekerken, Cunningham (1993) ise borç yükü artışının işgücü ve sermaye verimliliğini etkilemediğini dile getirerek borç yükü artışı ve büyüme arasındaki negatif ilişkiyi desteklemiştir. Fasu (1996) da, borç yükünün büyümeyi engellediği hipotezini tespit ederek borcun yatırıma etkisinin monotonik olmadığını, borcun etkisinin düşük yatırım düzeylerinde pozitif olup belli bir eşik sonrasında ise negatif olmaya başladığını belirtmiştir. Bunlardan farklı olarak, Mbire ve Atingi (1997), borç ve büyüme arasındaki ilişkiyi araştırdıkları çalışmalarında sermaye stokunun artışı, yatırım oranını arttırdığında büyümenin de artacağını dile getirmişlerdir.

Chowdhury (2001), dış borç stokundan büyümeye doğru anlamlı bir negatif nedensellik ilişkisi bulmuştur. Dolayısıyla, dış borçluluğun büyümeyi engelleyerek aralarında negatif bir ilişki olduğunu belirtmiştir. Sıddıqui ve Malik (2001), yatırımın GSYİH'ye oranının katsayısının pozitif olduğunu bulmuşlar ve dış borç servisinin artmasının yatırımı etkileyerek büyümeye etkisinin pozitif olduğunu belirtmişler, bunu ise sermaye birikiminin büyümenin temel kaynağı olduğu şeklindeki hipoteze dayandırmışlardır. Ramakrishna (2002), Etiyopya'da borç ve büyüme arasındaki ilişkiyi araştırmış ve ülke, borç-Laffer eğrisinin yanlış tarafında iken borç uzantısı hipotezini destekleyerek iki değişken arasında doğrusal olmayan bir ilişki kadar negatif bir ilişki öngörmüştür. Kısaca, borç stoku arttıkça GSYİH'nin artış oranı (büyüme) düşmektedir. Schalarek (2004), dış borcun kişi başına büyümeye doğrusal bir negatif etkisini bulurken, Presbitero (2005) ise dış borcun büyüme oranına etkisini araştırmış, borç servis ödemeleri, bütçe dengesinin kaynaklarını tükettiği için, dışlama etkisinin varlığını (daha düşük yatırım nedeniyle daha düşük büyüme oranını) belirtmiştir. Ayrıca, borç stokunun yatırım ve dolayısıyla, büyüme oranında sahip olduğu negatif bir etki nedeniyle borç uzantısı etkisinin varlığı sonucuna ulaşmışlardır. Sen, Kasibhotlo ve Stewart (2007), Latin Amerika ülkelerinde borç uzantısı etkisinin ve dolayısıyla yüksek dış borç düzeyinin büyümeyi şiddetli biçimde zedelediğini ve etkinin Asya bölgesinde 1lımlı biçimde negatif olduğunu göstermiştir. Hameed, Ashraf ve Chaudhory (2008), Pakistan'da borç servis yükünün işgücü ve sermaye verimliliğinde negatif bir etkiye sahip olduğunu ve dolayısıyla, büyümeyi olumsuz etkilediğini ortaya koymuştur. Çalışmasında, borç yükünden GSYİH'ye doğru işleyen bir nedensellik ilişkisi olduğuna işaret etmiştir. Daud ve Podivinsky (2011), bölgesel yakınsama anlamında mekânsal bir yöntem kullanarak dış borcun büyümeye etkisini 
incelemiş ve beş farklı bölgede bu iki değişken arasında negatif bir ilişki bularak komşu ülkeler arasında yayılmacı büyümenin varlığını da desteklemiştir.

Ampirik çalışmaları ikinci olarak, borç için bir eşik değer hesaplayarak borcun büyümeye doğrusal olmayan etkisini konu alan çalışmalar oluşturmaktadır. Clements, Bhattacharya ve Nguyen (2003), yüksek borçlu yoksul ülkelerde diş borç stokundaki azalmanın kamu yatırımındaki artışa olan etkileri üzerinden kişi başına geliri arttırabileceğini belirtmiştir. Borç uzantısı için ampirik bir destek sağlamakla birlikte belli bir eşiğin ötesinde (GSYİH'nin \%50'si) daha yüksek diş borcun beraberinde daha düşük kişi başına gelir artış oranlarını getirdiğini (negatif olmaya başladığını) öngörmüştür. Bhattacharya ve Clements (2004), düşük gelirli ülkelerde yüksek borç düzeylerinin büyümeyi daraltabildiğini, ancak, belli bir eşik değere (GSYİH'nin \%50'si) ulaştıktan sonra bunun olduğunu göstermişlerdir. Çalışmalarında borç uzantısı hipotezine destek vermekle birlikte, borç servisinin büyümeye etkisinin kamu yatırımını dışlayarak dolaylı biçimde gerçekleştiğini belirtmişlerdir. Pattillo, Poirson ve Ricci (2004), borcun büyümeyi faktör birikimi mi yoksa toplam faktör verimliliği artışı üzerinden mi etkileyip etkilemediğini araştırmışlardır. Çalışmalarında yüksek borcun hem fiziki sermaye birikiminde hem de toplam faktör verimliliği artışında güçlü bir negatif etki üzerinden büyümeyi olumsuz etkilediğini tespit etmişlerdir. Bununla birlikte, borcun düşük düzeylerinde büyümede pozitif, ancak, belli bir eşik değerin üzerinde ise ilave borcun, büyümede negatif bir etkiye sahip olduğunu belirtmişlerdir. Adam ve Bevan (2005), bütçe açıkları ve büyüme arasındaki ilişkiyi inceleyerek, GSYİH'nin \%1,5'u kadar bir açık düzeyinde özellikle düşük ve orta gelirli ülkelerde bir eşik etkisi bulmuşlardır. Bütçe açıklarının bu seviyeye düşürülmesi büyüme kazancı yaratırken, bu etki daha fazla mali daralmada ise ortadan kalkmaktadır.

Cecchetti, Mahonty ve Zampoli (2010), kamu borç stokunun GSYİH’ye oranının eşik değerini \%77,1 bulmuştur. Borç, bu eşik değerin altında iken ilave borç büyümeyi arttırırken eşik düzeyini aşan kamu borç stokunun GSYİH'ye oranının etkisi ise büyüme yönünden maliyetlidir. Checherita ve Rother (2010), avro bölgesinde, kamu borcunun GSYİH'ye oranı ile büyüme artış oranı arasındaki ilişkiyi araştırmış ve bunlar arasında yüksek bir anlamlı (\%90) doğrusal olmayan ilişki bulmuşlardır. Bu durum, borç stoku bu oranın üzerinde iken büyüme oranının azaldığı anlamına gelmektedir. Ayrıca, kamu borcunun büyüme oranında sahip olduğu kanalların, özel tasarruf, kamu yatırımı, toplam faktör verimliliği ve uzun vadeli nominal ve reel faiz oranları olduğunu belirtmişlerdir. Balassone, Francese ve Pace (2011), İtalya'da kamu borç stokunun GSYİH'ye oranı ile reel kişi başına gelir artışı arasındaki ilişkiyi araştırmışlar, bir eşik etkisi (\%100) yoluyla bu iki değişken arasındaki negatif ilişsinin kamu yatırımının azalması üzerinden olduğunu bulmuşlardır. Son olarak, Greenidge vd. (2012), kamu borç stokunun GSYİH'ye oranındaki artışların büyümeye etkisini inceledikleri çalışmalarında, belirtilen eşik değerin \%56 olduğunu tespit etmişlerdir.

Ampirik çalışmaların konuyu incelediği bir diğer alanı ise borçların büyümeye etkilerini analiz ederken politika ve kurumların ne durumda olduğunu tartışan çalışmalar oluşturmaktadır. Bunlardan Cordella, Ricci ve Ruiz-Arranz (2005), borç ve büyüme 
arasındaki doğrusal olmayan ilişkinin ülkelerin özelliklerine göre değişmesine izin verildiğinde, iyi politikalı ve kurumlu ülkelerde borç uzantısı eşiğinin $\% 15$ ile $\% 30$ arasında iken, kötü politikalı ve kurumlu ülkelerde ise bu eşiğin daha düşük olduğunu bulmuşlardır. Öyle ki, yüksek borçlu ülkelerde borç yardımı yeterince büyük ve bu ülkeler iyi iktisadi ve politika koşullarına sahip iken bunun büyümeyi arttırıcı olduğunu belirtmişlerdir. Benzer olarak, Presbitero (2008), dış borç ve büyüme arasındaki ilişkinin ülkelerin sahip oldukları kurumlar ve politikalara bağlı olduğunu vurgulamıştır. Kötü politikalı ülkelerde dış borç ve büyüme arasında anlamlı bir ilişki yok iken, iyi politikalı ülkelerde ise bu iki değişken arasında negatif ve anlamlı bir ilişki (yüksek borcun büyümeyi düşürmesi) bulmuştur. Dolayısıyla, bu çalışmalar, borç ve büyüme arasındaki ilişkinin politika ve kurumsal yapılara göre farklılaştığını ortaya koymaktadır.

\section{Model, Veri Seti ve Yöntem}

Çalışmanın bu kısmında veri elde edilebilirliğine bağlı olarak, Avrupa Birliği’ne üye seçilmiş on üç (AB-13) ülkede 1970-2011 döneminde kamu borç stokunun büyümeye etkisi panel veri yöntemiyle analiz edilmektedir ${ }^{3}$. Çalışmada kullanılan veri seti, International Financial Statistics (IFS) ve Dünya Bankası'ndan alınmış olup kamu borcunun büyümeye etkisi aşağıdaki model yardımıyla tahmin edilmiştir:

$$
g_{y i t}=\alpha_{i t}+\beta X_{i t}^{\prime}+\varepsilon_{i t}
$$

Burada $g_{y}$ bağımlı değişkeni, $\alpha$ bir skaları, $X$ açıklayıcı değişkenler $(\mathrm{k})$ vektörünü ve alt indisler $(i=1 \ldots \ldots N$ ve $t=1 \ldots \ldots . T)$ yatay kesit ve zaman boyutların göstermektedir. $\beta, k x 1$ ve $X_{i t}$ ise $k$ açıklayıcı değişkene ilişkin $i$. gözlemdir. Bu denklem, ülkeler arasında bir ayrım yapmamaktadır. Bu model, sabit katsayılar, kesişimler ve eğimleri nitelemektedir (Sen, Kasibhotlo ve Stewart, 2007: 6). Modelde, $g_{y}$ kişi başına GSYİH'da bir dönem gecikmeli artış oranını (büyüme oranını) ${ }^{4}$ ve $X$ ise başta kamu borç stokunun GSYİH'ye oranı ( $r d e b t)$ olmak üzere diğer kontrol değişkenlerini ((tasarrufların GSYİH'ya oranı (rsaving), kamu tüketiminin GSYİH'ye oranı (gcons), nüfus artış hızı (popgrowth), gecikmeli GSYİH (koşullu yakınsama, $l g d p$ ), enflasyon oranı (inf), toplam faktör verimliliği ( $t f p)$, yaş bağımlılık oranı (adepend), reel faiz oranı (rinterest), kamu bütçe dengesinin GSYİH'ya oranı ( $r g b u d b a l)$, kamu borç stokunun GSYİH'ye oranının \%30'un altında (dum_30) ve \%90'nın üzerinde (dum_90) olduğunu gösteren iki adet kukla değişkeni) temsil etmektedir.

3 Çalışmada Belçika, Danimarka, İrlanda, Yunanistan, İspanya, Fransa, İtalya, Hollanda, Avusturya, Portekiz, Finlandiya, İsveç, İngiltere olmak üzere Avrupa Birliği’ne üye on üçülke kullanllmıştır.

4 Büyüme oranı, cari ve bir dönem gecikmeli gelir arasindaki farkın, bir dönem gecikmeli gelire bölünüp 100 ile çarpılmasıyla bulunur. 
Aşağıda açıklayıcı değişkenler ve literatürle ilişkili olarak beklenen işaretleri açıklanmaktadır:

- Kamu borç stokunun GSYİH'ye oranı (rdebt): Yüksek borcun büyüme oranını düşürmesi beklenir ve bu değişken negatif bir katsayıya sahip iken, borç uzantısının büyümeyi zedelediği sonucuna ulaşılır (Sen \& Kasibhotlo \& Stewart, 2007: 8). Ancak, borcun büyümeye etkisi, belli bir eşik değere kadar pozitif iken, belli bir eşik değer sonrasında ise negatif olmaya başlayabilmektedir (Presbitero, 2008: 9, 10). Çalışmada bunun ölçülmesi için belirtildiği gibi iki farklı kukla değişken kullanılmıştır. Bu oran \%30'un altında iken borcun büyümeye etkisinin pozitif, ancak, bu oran \%90'nın üzerinde iken ise Reinhart ve Rogoff (2010)'un belirttiği gibi negatif olması beklenmektedir (Kumar \& Woo, 2010: 17).

- Tasarrufun GSYIH'ye oranı (rsaving): Bu oranın büyümeye etkisinin pozitif olması beklenmektedir (Sıddıqui \& Malik, 2001: 684).

- Kamu tüketiminin GSYİH'ye oranı (gcons): Kamusal büyüklüğü ölçmektedir. Kamusal büyüklük veya kamu tüketimi arttıkça eğer bunlar yatırımlara ayrılıyor ise büyüme oranının artması beklenir (Chowdhury, 2001: 8; Kumar \& Woo, 2010: 11).

- Nüfus artış hızı (popgrowth): Çalışmada, nüfus artışı, üretim sürecinde işgücü girdisinin artış oranının bir göstergesi olduğu için kullanılır (Clements, Bhattacharya ve Nguyen, 2003: 7). Nüfus artışının etkisi, nüfus büyüme sürecini engeller ise negatif olup ekonomideki verimliliği düşüreceğinden, bu hız yüksek iken büyüme oranının düşmesi beklenir (Siddıqui \& Malik, 2001: 685; Presbitero, 2008: 9).

- Gecikmeli GSYİH ( $\lg \boldsymbol{d} \boldsymbol{p})$ : Modelde açıklayıcı bir değişken olarak, reel kişi başına gelirin yer almasının nedeni, hem ülkelerin zaman boyunca ortak bir gelir düzeyine yakınsayıp yakınsamadığını test etmek (Clements \& Bhattacharya \& Nguyen, 2003: 7) hem de ihmal edilen değişken yanlılığ1 ve ters nedenselliği dikkate almaktır (Greenidge vd., 2012: 11). Koşullu yakınsamayı test eden bu değişken ve büyüme arasında negatif bir ilişkinin varlığı, neoklasik ve bazı içsel büyüme modelleri ile tutarlı olan koşullu yakınsama hipotezini destekler. Bu bağlamda, kişi başına gecikmeli gelirin logaritmik katsayısının yakınsama hipotezinin desteklemesi için negatif olması beklenir (Chowdhury, 2001: 5; Siddıqui \& Malik, 2001: 685).

- Enflasyon oranı (inf): Çalışmada paranın nakit avans (cash-in-advance) modelinde daha yüksek beklenen enflasyon oranının sermaye yatırımlarını azalttığı tahmin edildiği için enflasyon oranına yer verilir ve enflasyon oranı yüksek iken, büyüme oranının düşmesi beklenir (Chowdhury, 2001: 5; Presbitero, 2008: 9). 
Berke, B. (2016), “Avrupa Birliği’nde Kamu Borç Stokunun Ekonomik Büyümeye Etkisi: Panel Veri Analizi”, Sosyoekonomi, Vol. 24(27), 121-137.

- Toplam faktör verimliliği ( $\boldsymbol{t} \boldsymbol{f} \boldsymbol{p})$ : Yüksek borç yatırımın etkinliğini düşürerek büyümeyi azalttığı için borcun büyümeye etkisi, sermaye etkinliği üzerinden değil toplam faktör verimliliği üzerinden olabilmektedir. Dolayısıyla, bu negatif etki ise toplam faktör verimliliğindeki düşmeyle işleyebildiğinden bu değişkene yer verilmektedir (Presbitero, 2008: 10).

- Yaş bağımlılık oranı (adepend): Eğitimi temsil etmek üzere kullanılan yaş bağımlılık oranı arttıkça özel tasarruf oranı azaldığı için büyüme oranının düşmesi beklenir (Presbitero, 2008: 9; Checherita \& Rother, 2010: 16).

- Reel faiz oranı (rinterest): Enflasyon ile mali ve parasal politika karışımının etkilerini yakaladığı için uzun vadeli reel faiz oranı da kullanılmaktadır (Checherita \& Rother, 2010: 15). Bu oran arttıkça yatırımlar azalacağından büyüme oranının düşmesi beklenmektedir.

- Kamu bütçe dengesinin GSYİH'ye oranı (rgbudbal): Bütçe açığı değişkeni, mali açıkların uzun dönemli büyümeyi negatif biçimde etkilediği bulgusunu dikkate almak için kullanılmaktadır. Bu açık, kamusal tasarrufu dışlayıp kaynak girişi, yolsuzluk veya kaynak çıkışını teşvik eder ise büyümedeki etkisinin negatif olması beklenmektedir (Sıddıqui \& Malik, 2001: 684; Kumar \& Woo, 2010: 11).

Panel veri yöntemleri, sabit ve tesadüfi etkilerle gerçekleştirilir. Çalışmada, her iki model arasındaki seçim için bazı ön istatistiksel testler yapılmaktadır. Modellerdeki tüm değişkenler ülkeler ve zamanlar arasında değişebildiğinden asıl nokta, serilerin ülkeler ve zamanlar arasında toplulaştırılıp toplulaştırılmadığıdır. Bu etkilerin ortak anlamlılığının belirlenmesi için Chow testi kullanılır. Bu testin boş hipotezi etkin tahmincinin "havuzlanmış EKK" olması iken, alternatif hipotezi ise "sabit etki" (fixed effect) modelinin varlığıdır. Çalışmada, boş hipotezin reddi ise sabit etki modelinin havuzlanmış EKK'ya tercih edilmesi gerektiği anlamına gelir. Ayrıca, boş hipotezi tesadüfi etkinin yokluğu şeklinde olan Breusch Pagan testinde, bu hipotezin kabul edilmesi havuzlanmış EKK modelinin tesadüfi etki modeline tercih edilmesi gerektiğini gösterir. Son olarak, modelde sabit etki mi yoksa tesadüfi etki modelinin mi uygun olduğuna "Hausman spesifikasyon testi" yapılarak karar verilir ve bu testte, boş hipotezin reddi sabit etki modelinin tesadüfi etki modeline tercih edilmesi gerektiğini ortaya koyar (Baltagi, 2004). Çalışmada modellerin tahmininden önce değişen varyans ve otokorelasyon sorunları da değerlendirilir. İlk olarak olasılık oranı (likelihood ratio, LR) testi, hata varyanslarının ülkelere özgü olduğunu belirten sabit varyanslılık (homoskedasticity) boş hipotezini reddeder. Değişen varyans testinin yanısıra, Wooldridge otokorelasyon testi ise birinci dereceden (first order) otokorelasyon yok şeklindeki boş hipotezin reddedildiğini söylemektedir.

Modelde değişen varyans ve serisel korelasyon testleri, tutarlı ve etkin tahmin ediciler elde etmek için "uygun genelleştirilmiş en küçük kareler yöntemine” de (feasible generalized least squares, FGLS) karşılaştırma için yer verilmesi gerektiğine işaret etmektedir. Beck ve Katz (1995) FGLS'in dayandığ yatay kesit sayısından $(N)$ yüksek olduğunda optimal olabileceğini dile getirmişlerdir. 
Çalışmada kullanılan tüm modellerde ülke başına yıllık gözlem sayısı $(T)$ ülke sayısından $(N)$ büyük olduğu için FGLS yöntemine de yer verilmektedir. Ancak, yapılan testlerin sonuçları (Chow \& Hausman testleri) sabit etki modelinin FGLS'e tercih edilmesi gerektiğini ortaya koyduğundan bu etkinin katsayıları yorumlanmakta ve AB-13'e ait panel veri analizinin sonuçları Tablo 1'de sunulmaktadır.

Tablo: 1

\section{Panel Regresyon Sonuçları}

\begin{tabular}{|c|c|c|c|}
\hline Bağımsız Değişkenler & Havuzlanmış EKK & Sabit Etki & FGLS \\
\hline$r d e b t_{i t}$ & $\begin{array}{l}0.0001236 \\
(1.70)^{*}\end{array}$ & $\begin{array}{l}0.0001461 \\
(1.74)^{*}\end{array}$ & $\begin{array}{l}0.0001242 \\
(2.09) * *\end{array}$ \\
\hline rsaving $_{i t}$ & $\begin{array}{l}-0.0006185 \\
(-2.11) * * \\
\end{array}$ & $\begin{array}{l}0.0008054 \\
(1.34) \\
\end{array}$ & $\begin{array}{l}-0.0002372 \\
(-0.94)\end{array}$ \\
\hline gcons $_{i t}$ & $\begin{array}{l}-0.030991 \\
(-5.63) * * *\end{array}$ & $\begin{array}{l}-0.0339098 \\
(-4.34)^{* * *} \\
\end{array}$ & $\begin{array}{l}-0.0255076 \\
(-5.03) * * *\end{array}$ \\
\hline popgrowth $_{i t}$ & $\begin{array}{l}-0.0077593 \\
(-3.20) * * * \\
\end{array}$ & $\begin{array}{l}-0.013049 \\
(-4.97) * * * \\
\end{array}$ & $\begin{array}{l}-0.0065272 \\
(-2.62) * * * \\
\end{array}$ \\
\hline $\lg d p_{i t}$ & $\begin{array}{l}-0.0454888 \\
(-7.12) * * * \\
\end{array}$ & $\begin{array}{l}-0.1609016 \\
(-2.62)^{* * *}\end{array}$ & $\begin{array}{l}-0.0363547 \\
(-6.15)^{* * *}\end{array}$ \\
\hline $\inf f_{i t}$ & $\begin{array}{l}-0.0004274 \\
(-6.16) * * *\end{array}$ & $\begin{array}{l}-0.0005639 \\
(-4.53) * * * \\
\end{array}$ & $\begin{array}{l}-0.000498 \\
(-7.28) * * * \\
\end{array}$ \\
\hline$t f p_{i t}$ & $\begin{array}{l}0.0005692 \\
(3.81)^{* * *}\end{array}$ & $\begin{array}{l}0.0014784 \\
(4.37)^{* * *}\end{array}$ & $\begin{array}{l}0.000699 \\
(4.48) * * *\end{array}$ \\
\hline adepend $_{i t}$ & $\begin{array}{l}0.000675 \\
(2.64) * * * \\
\end{array}$ & $\begin{array}{l}-0.0005987 \\
(-1.57) \\
\end{array}$ & $\begin{array}{l}0.0003674 \\
(1.47) \\
\end{array}$ \\
\hline rinterest $_{i t}$ & $\begin{array}{l}0.0008159 \\
(2.29)^{* *}\end{array}$ & $\begin{array}{l}0.0004719 \\
(1.20)\end{array}$ & $\begin{array}{l}0.0011168 \\
(3.38)^{* * * *}\end{array}$ \\
\hline rgbudbal $_{i t}$ & $\begin{array}{l}0.0023286 \\
(7.71)^{* * *}\end{array}$ & $\begin{array}{l}0.0024917 \\
(7.43)^{* * *}\end{array}$ & $\begin{array}{l}0.0021486 \\
(7.51)^{* * * *}\end{array}$ \\
\hline dum_30 & $\begin{array}{l}-0.0107491 \\
(-2.92)^{* * *}\end{array}$ & $\begin{array}{l}-0.0088856 \\
(-2.44)^{* *}\end{array}$ & $\begin{array}{l}-0.0092061 \\
(-2.94) * * *\end{array}$ \\
\hline dum_90 & $\begin{array}{l}-0.0043917 \\
(-1.14)\end{array}$ & $\begin{array}{l}-0.0042404 \\
(-1.10)\end{array}$ & $\begin{array}{l}-0.005385 \\
(-1.72) * * \\
\end{array}$ \\
\hline Sabit Terim & $\begin{array}{l}0.068521 \\
(2.82)^{* * *}\end{array}$ & $\begin{array}{l}0.2251704 \\
(3.12)^{* * *}\end{array}$ & $\begin{array}{l}0.055114 \\
(2.35)^{* *} \\
\end{array}$ \\
\hline $\mathrm{R}^{2}$ & 0.2565 & 0.3218 & \\
\hline F İstatistiği & $15.32 * * *$ & $20.60 * * *$ & \\
\hline Chow Testi $(53,480)$ & & $\begin{array}{l}8.08 \\
(0.000)^{* * *}\end{array}$ & \\
\hline LR Değişen Varyans Testi $\chi^{2}(12)$ & & & $\begin{array}{l}78.36 \\
(0.000)^{* * *}\end{array}$ \\
\hline Wooldridge Otokorelasyon Testi $\mathrm{F}(1,12)$ & & & $\begin{array}{l}92.850 \\
(0.000) * * *\end{array}$ \\
\hline Wald İstatistiği $\chi^{2}(12)$ & & & $\begin{array}{l}189.38 \\
(0.000)^{* * *}\end{array}$ \\
\hline Breusch Pagan Testi $\chi^{2}(1)$ & & & $\begin{array}{l}0.00 \\
(1.000) \\
\end{array}$ \\
\hline Hausman Spesifikasyon Testi $\chi^{2}(12)$ & & & $\begin{array}{l}84.53 \\
(0.000)^{* * *}\end{array}$ \\
\hline Grup Say1s1 & 13 & 13 & 13 \\
\hline Gözlem Sayıs1 & 546 & 546 & 546 \\
\hline
\end{tabular}

Not: Burada “*”, ”**”, ”***”, strasılla \%10, \%5 ve \%1 anlamlllı düzeylerini göstermektedir. 
Berke, B. (2016), “Avrupa Birliği'’nde Kamu Borç Stokunun Ekonomik

Büyümeye Etkisi: Panel Veri Analizi”, Sosyoekonomi, Vol. 24(27), 121-137.

\section{Analiz Sonuçları}

Tablo 1'de sabit etki modelinin sonuçlarına bakıldığında başlangıç kamu borcu ve büyüme arasında pozitif ve anlamlı bir ilişki vardır. Bu durum, Avrupa Birliği ülkelerinin (AB-13), borç-Laffer eğrisinin yukarıya doğru eğimli tarafında olduklarını ve borç uzantısı hipotezinin desteklenmediğini göstermektedir. Bu sonuç, Cohen (1993) ile benzerlik gösterirken, Chowdhury (2001), Bhattacharya ve Clements (2004), Pattillo, Poirson ve Ricci (2004), Adam ve Bevan (2005), Sen, Kasibhotlo ve Stewart (2007), Hameed, Ashraf ve Chaudhory (2008), Checherita ve Rother (2010), Kumar ve Woo (2010), Balassone, Francese ve Pace (2011) ile Daud ve Podivinsky (2011)'nin bulguları ile çelişmektedir. Modelde, belirtildiği gibi başlangıç kamu borcunun yanı sıra başka iktisadi ve finansal değişkenlere de yer verilmiştir. Bu değişkenlerden reel tasarruf oranı ile büyüme oranı arasında pozitif, ancak istatistiki olarak anlamsız bir ilişki çıkmakla birlikte, işareti beklenen yönlü gerçekleşmiş ve Daud ve Podivinsky (2011)'nin bulguları ile benzerlik göstermiştir.

Kamu büyüklüğünü ölçen kamu tüketiminin GSYİH'ye oranı, negatif ve anlamlı çıkmıştır. Bu durum, avro bölgesinde kamu tüketiminde ve dolayısıyla kamu büyüklüğünde bir artışın büyümeyi azaltıcı yönde etkilediğini göstermektedir. Nüfus artış hızı arttıkça iktisadi büyüme oranı beklendiği gibi düşmekte, bu durum, ele alınan ülke grubunda sermayeden işgücüne doğru bir ikame olacağını ortaya koymaktadır. Dolayısıyla, bu sonuç, Clements, Bhattacharya ve Nguyen (2003), Cordella, Ricci ve Ruiz-Arranz, (2005) ile Daud ve Podivinsky (2011)'nin bulgularıyla benzerlik göstermiştir. Koşullu yakınsama hipotezini destekleyen kişi başına gecikmeli çıktının logaritmik katsayısı geleneksel büyüme modellerinin öngörüleri ile tutarlı olarak negatif ve anlamlı çıkmıştır. Bu durum, tüm Avrupa Birliği'ne üye eski üyeler için yakınsama hipotezinin varlığını öngörmekte ve Chowdhury (2001), Clements, Bhattacharya ve Nguyen (2003), Cordella, Ricci ve Ruiz-Arranz, (2005) ile Daud ve Podivinsky (2011)'nin bulgularıyla tutarlı çıkmaktadır.

Enflasyon oranının artması beklendiği gibi sermaye yatırımlarının azalmasına neden olduğu için büyüme oranını düşürmektedir. Bu bulgu, Cordella, Ricci ve Ruiz-Arranz (2005)'ın çalışması ile tutarlı çıkmaktadır. Toplam faktör verimliliğinin artması, beklendiği gibi büyümeyi arttırmakta ve istatistiki olarak anlamlı ve pozitif bir işareti vermektedir. Çalışmada eğitimi temsil etmek üzere kullanılan yaş bağımlılık oranı arttıkça büyüme oranının beklendiği gibi özel tasarrufta negatif bir etki yarattığı için düş̧üğü; ancak, ilişkinin anlamsız olduğu görülmektedir. Bu bulgu, Checherita ve Rother (2010)'in bulguları ile uyum sağlamaktadır. Uzun vadeli reel faiz oranı ile büyüme arasında beklendiğinin tersine pozitif yönlü, ancak, anlamsız bir ilişki çıkmaktadır. Reel bütçe dengesi ile büyüme arasındaki iliş̧ki dışlama etkisine zıt olarak pozitif yönlü ve anlamlı çıkmıştır. Bu mali gösterge, Avrupa Birliği'ne üye ülke grubunun mali konsolidasyon ihtiyacının olmadığını ortaya koyarak iyi mali politikaların büyümeye pozitif yönlü etkilerini göstermekte ve Clements, Bhattacharya ve Nguyen (2003), Cordella, Ricci ve Ruiz-Arranz, (2005) ile Presbitero (2005)'nun bulgularını desteklemektedir. Kamu borç stokunun \%30'un altında ve \%90'nın üzerinde olduğu durumları temsil eden dum_30 ve dum_90 kukla değişkenlerinin her ikisi de negatif işaretlidir: dum_30 değişkeni beklenenden farklı olarak negatif çıkmıştır. 
Diğer yandan, dum_90 kukla değişkeninin negatif çıkması, Reinhart ve Rogoff (2010)'un kamu borç stokunun $\% 90$ eşik değeri aştıkça büyüme oranını düşürdüğü fikrini desteklemekle birlikte, aralarındaki ilişkinin anlamsız olduğu tespit edilmiştir. Bulgular, ele alınan ülke grubunda kamu borç stokunun yüksek bir değerinin iktisadi daralmaya neden olduğunu ortaya koymaktadır. Bir diğer ifadeyle, ağır bir borç yükü, ülkelerin yarattığı kaynaklarda zımni bir vergi rolü oynamaktadır. Böylece, onların kalitesi kadar ulusal ve yabancı yatırımların büyüklüğünü azaltmakta ve politika reformları için negatif teşvikler yaratmaktadır (Cordella \& Ricci \& Ruiz-Arranz, 2005: 4). Diğer yandan, bu bulgu, borç uzantısı hipotezini de desteklemektedir. Borç ödemelerinin artması, verimli yatırımları azaltarak sermaye formasyonunu caydırmaktadır. Böyle durumlarda, borçlu ülke, sadece kısmen üretimdeki ve/veya ihracatlardaki herhangi bir artıştan kar sağlamakla birlikte, yeni yatırımlar üstlenmek için ülkenin borçlanma teşvikleri önemli ölçüde zayıflamaktadır. Öyle ki, borç servis ödemesi, üretimdeki artışlarda ilave iyileşmelerin bir oranı olarak arttığında borçlanan ülkenin kredi değerliliği zarar görmektedir. Bu güçlükler nedeniyle ağır bir borç altında olan ülkeler için büyük altyapı, yeni projeler ve eski yatırımlarla devam etmek imkânsız olmaya başlamaktadır (Hameed \& Ashraf \& Chaudhory, 2008: 137, 138). Bu bulgular, borç için eşik değer hesaplayan Cecchetti, Mahonty ve Zampoli (2010), Checherita ve Rother (2010), Kumar ve Woo (2010) ile Balassone, Francese ve Pace (2011)'nin sonuçları ile örtüşmektedir.

\section{Sonuç}

Yüksek borç yükü, uluslararası piyasada rekabet kaybı, makroekonomik dengesizlik ve kaynakların yanlış yönetiminden kaynaklanmaktadır. Borç ve büyüme arasında belli bir eşik değerden sonra negatif bir ilişkinin varlığı, borçlanılan kaynakların yanlış dağıtıldığını veya tüketimde kullanıldığını gösterebilmekle birlikte, borç yükünün verimliliğe süre gelen olumsuz etkileri, ülkenin gelecekte borcunun geri ödeme gücünün azalacağı anlamına gelmektedir (Clements \& Bhattacharya \& Nguyen, 2003; Hameed \& Ashraf \& Chaudhory, 2008).

Bu çalışmada AB-13'de, 1970-2011 döneminde “kamu borç stokunun GSYİH’ye oranındaki bir artışın büyümeyi ne yönde etkilediği”" panel veri yöntemiyle sorgulanmıştır. Genel olarak bakıldığında reel borç stoku artışı başlangıçta büyüme oranını arttırırken, \%30 eşik borç düzeyinden sonra bu artış büyümeyi düşürmektedir. Belli düzeyde borçlanma verimlilik artışı üzerinden ekonomik büyümeyi teşvik ederken Reinhart ve Rogoff(2010)'un işaret ettiği gibi diğer kontrol değişkenlerinin etkileri kontrol edildikten sonra kamu borç stoku GSYİH'ye oranı \%90 eşik değerinin üzerinde olduğunda büyüme oranını düşürmektedir. Bu sonuç, Avrupa Birliği'ne üye ülkelerde hassas politika önerileri çizmede önemlidir.

Avro bölgesinde son yıllarda yaşanan borç krizi, yüksek borç düzeylerinin mali sürdürülebilirlik ve ekonomik büyüme yönünden bazı sonuçlar yaratabileceğini göstermiştir. Kriz dönemlerinde ülkeler, sermaye girişleri azalırken, gelirlerine kıyasla harcama düzeyleri arttığı için borç biriktirme eğiliminde olup özellikle sermayelerini 
arttırma güçlükleri sonucu borç yükleri ve borç yönetim problemleri artmaktadır. Diğer yandan, böyle bir ortamda ülkelerdeki yatırımcılar borçlarını geri ödeyemedikleri gibi borçların ne kadarlık bir kısmının ülkelerin kendi kaynakları ile karşılanacağına ilişkin belirsizlikler veri iken, yeni yatırımlar yapmaktan da kaçınabilirler. Tüm bunlar bir yandan, yeni ulusal ve yabancı yatırımların yapılmasını caydırarak sermaye stoku birikimini yavaşlatırken, diğer yandan, toplam faktör verimliliğini de azaltacağından üretimde azalmalar meydana gelebilmektedir. Büyüme oranının düşmesi ise borcun geri ödenmesini sağlamak için yeterli finansman elde edilmemesi anlamına gelir. $\mathrm{Bu}$ koşullarda hükümetlerden yeni politika reformları aracılığı ile kaynakların etkin kullanımını ve teknolojik iyileşmeyi sağlaması beklenmektedir (Greenidge vd., 2012).

$\mathrm{Bu}$ çalışmanın gerektirdiği mevcut ekonometrik kısıtların zaman içinde yeni teknikler ve modeller yardımı ile desteklenmesi, gelecek çalışmalar açısından ise kamu borç stoku ve diğer mali değişkenlerdeki oynaklıkların büyüme oranında yaratabileceği karşılıklı etkilerin değerlendirilmesi önem taşımaktadır.

\section{Kaynaklar}

Adam, C.S. \& D.L. Bevan (2005), "Fiscal Deficits and Growth in Developing Countries", Journal of Public Economics, 89, 571-597.

Balassone, F. \& M. Francese \& A. Pace (2011), Public Debt and Economic Growth in Italy, $<$ http://w3.uniroma1.it/ecspc/Balassone_Francese_Pace_draft_020911.pdf>, 06.11.2011.

Baltagi, B. (2004), Econometric Analysis of Panel Data, Third Edition, New York: John Wiley and Sons.

Barrios, S. \& S. Langedijk \& L.R. Pench (2010), EU Fiscal Consolidation after the Financial Crisis: Lessons from Post Experiences, <http://www.voxeu.org/index.php?q=node5593>, 12.09.2011.

Beck, N. \& J.N. Katz (1995), "What to do (and not to do) With Time Series Cross-Section Data", The American Political Science Review, 89(3), 634-347.

Bhattacharya, R. \& B. Clements (2004), "Calculating the Benefits of Debt Relief", Finance and Development, 12, 48-50.

Cecchetti, S.G. \& M.S. Mohanty \& F. Zampolli (2010), "The Future of Public Debt: Prospects and Implications", BIS Working Paper, 300, 1-22.

Checherita, C. \& P. Rother (2010), "The Impact of High and Growing Government Debt on Economic Growth: An Empirical Investigation for the Euro Area”, European Central Bank Working Paper Series, 1237, 1-40.

Clements, B. \& R. Bhattacharya \& T.Q. Nguyen (2003), "External Debt, Public Investment and Growth in Low-Income Countries", IMF Working Paper Series, 03/249, 1-24.

Chowdhury, A.R. (2001), "External Debt and Growth in Developing Countries, A Sensitivity and Casual Analysis”, WIDER Discussion Paper, 2001/95, 1-22.

Cohen, D. (1993), “Low Investment and Large LDC Debt in the 1980's", The American Economic Review, 83(3), 437-449. 
Connolly, M. \& J. Devereux (1995), “The Natural Real Exchange Rate”, the Fundamental Determinants of the Exchange Rate, Jerome Stein (ed.), Oxford University Press.

Cordella, T. \& L.A. Ricci \& M. Ruiz-Arranz (2005), "Debt Overhang or Debt Irrelevance? Revisiting the Debt Growth Link", IMF Working Paper Series, 05/223, 1-55.

Cunningham, R.T. (1993), "The Effects of Debt Burden on Economic Growth in Heavily Indebted Developing Nations", Journal of Economic Development, 18(1), 115-126.

Daud, S.N.M. \& J.M. Podivinsky (2011), "Debt-Growth Nexus: A Spatial Econometrics Approach for Developing Countries", Transition Studies Review, 1, 1-15.

Diamond, P.A. (1965), "National Debt in a Neoclassical Growth Model", The American Economic Review, 55, 1126-1150.

Easterly, W.R. (2001), "Growth Implosions and Debt Explosions: Do Growth Slowdowns Cause Public Debt Crises?", Contributions to Macroeconomics, 1(1), 1-24.

Greenidge, K. \& R. Craigwell \& C. Thomas \& L. Drakes (2012), "Threshold Effects of Sovereign Debt: Evidence from the Caribbean", IMF Working Paper, 12/157, 1-22.

Fasu, A.K. (1996), "The Impact of External Debt on Economic Growth in Sub-Saharan Africa", Journal of Economic Development, 21(1), 93-118.

Hameed, A. \& H. Ashraf \& M.A. Chaudhory (2008), "External Debt and Its Impact on Economic and Business Growth in Pakistan", International Research Journal of Finance and Economics, 20, 132-140.

Irons, J. \& J. Bivens (2010), “Government Debt and Economic Growth”, EPI Briefing Paper, Economic Policy Institute, July, 1-9.

Krueger, A.O. (1987), “Debt, Capital Flows and LDC Growth”, The American Economic Review, 77(2), 159-164.

Krugman, P. (1988), "Financing vs. Forgiving a Debt Overhang”, Journal of Development Economics, 29, 253-268.

Kumar, M.S. \& J. Woo (2010), "Public Debt and Growth”, IMF Working Paper, 174, 1-46.

Mbire, B. \& M. Atingi (1997), "Growth and Foreign Debt: the Ugandan Experience", <http://www.aercafrico.org/DOCUMENTS/RPGG.PDF>, 14.02.2012.

Pattillo, C. \& H. Poirson \& L. Ricci (2004), "What are the Channels Through Which External Debt Affects Growth?", IMF Working Paper, 04/15, 1-33.

Presbitero, A.F. (2005), The Debt-Growth Nexus: An Empirical Analysis, <http://www.unicott.it/convegno/open_ekonomy/Allegati/debt_growth_presbitero.pdf>, 02.08.2011.

Presbitero, A.F. (2008), “The Debt-Growth Nexus in Poor Countries: A Reassessment”, The OpenAccess, Open-Assessment E-Journal, 2, 1-28.

Ramakrishna, G. (2002), "External Debt of Ethiopia: An Empirical Analysis of Debt and Growth", Journal of Business and Public Affairs, 29-35.

Reinhart, C.M. \& K.S. Rogoff (2010), "Growth in a Time of Debt”, American Economic Review: Papers and Proceedings, 100, 573-578.

Sachs, J. (1989), "The Debt Overhang of Developing Countries", in: Debt Stabilization and Development: Essays in Memory of Carlos Diaz Alejandro, ed. by Guillermo Calvo and others (Oxford: Basil Blackwell). 
Schalarek, A. (2004), Debt and Economic Growth in Developing Industrial Countries, <http://project.nek.lu.se/publications/workpap/Papers/WP05_34.pdf>, 30.12.2013.

Sen, S. \& K.M. Kasibhotlo \& D.B. Stewart (2007), "Debt Overhang and Economic Growth-the Asian and the Latin American Experiences", Economic Systems, 31, 3-11.

Siddıqui, R. \& A. Malik (2001), "Debt and Economic Growth in South Asia", The Pakistan Development Review, 40(4), 677-688.

Weng, C.K. \& E.Y. Meu \& L.K. Hoang \& T.K. Ean \& T.W. Shun (2011), Debt, Budget Deficit and Economic Growth of Malaysia, <http://eprints.utar.edu.my/282/1/FE-20110803715.pdf>, 27.02.2011. 
Berke, B. (2016), “Avrupa Birliği’nde Kamu Borç Stokunun Ekonomik Büyümeye Etkisi: Panel Veri Analizi”, Sosyoekonomi, Vol. 24(27), 121-137. 